\title{
Locational and Coverage Analysis of the Vital Registration Centres In Gombe State, Nigeria
}

\author{
Adam M. Abbas (PhD) \\ National Population Commission, 17 Ibrahim Dabo Rd, Kano
}

\begin{abstract}
This study assesses the levels of spatial accessibility, birth registration coverage and efficiency of vital registration centres in Gombe State. This was achieved through mapping out the locations and catchment areas of the existing vital registration centres; determining the influence of distance from vital registration centres and identifying areas where birth registration coverage is high. Both attribute and geometric data were used, and for the measurement of distance, Euclidean Distance was used. The study indicates that there is more concentration of a large number of the centres (11) on a small land mass $\left(53 \mathrm{~km}^{2}\right)$ of urban Gombe and hence making their availability in the rural areas distorted and accessibility poorer, especially by the rural communities of the five LGAs with larger land expanse of $8,964 \mathrm{~km}^{2}$ which shared the remaining 11 centres of the 22. The result of the study also shows that, with additional 7-10 registration centres in the five rural LGAs the average settlement distance would change from $24.12 \mathrm{~km}$ to $2.09 \mathrm{~km}$ (trekable distance). The study recommends the usage of location-allocation models for the optimum location of any new centres with sizeable catchment areas, full enforcement of the registration law and embarking on mass enlightenment campaigns and establishment of more centres.
\end{abstract}

Keywords: Accessibility, Efficiency, Euclidean Distance, Location-allocation Models, Vital Registration Centre,

\subsection{Background to the Study}

\section{Introduction}

There are four major sources of demographic data for planning processes. They are census, civil or vital registration, sample surveys and administrative records. Of these, census is the most comprehensive source, which provides the benchmark against which data from other sources, such as vital registration are measured ${ }^{[1]}$; [2]; [3]. A complete coverage of vital events provides data to complement the census and when sustained over time reduces the need for census taking [4].

Birth registration, an aspect of civil/vital registration is the official recording of the occurrence of birth in accordance with the laws of the country is therefore, not only a fundamental right in itself but also a key to ensuring the fulfillment of additional rights. Thus, such a system and its instruments value in safeguarding human right, contributes to the normal function of any society [1]; [5].

In Nigeria, vital registration took off in 1988 as a project after an elaborate preparation under the technical assistance of a United Nations expert in vital registration. Decree (now Act) No 39 of 1979 marked the commencement of universal registration system in the country. The births and deaths decree (now Act) no. 69 of 1992 saddled National Population Commission with the responsibility of establishing and maintaining a national system of registration of births, still births, deaths, marriages, divorces, migration etc and made the registration compulsory. Section 24 of the third schedule of the 1999 constitution further strengthened the registration system. The responsibility is therefore core to the Commission because it is a continuous and permanent exercise which transcends the census period. Thus, a fully functional civil registration system should be compulsory, universal, permanent and continuous and should ensure the confidentiality of personal data it collects, transmits and stores in an effective way, guarantees their quality and integrity. Generally, vital statistics generated from the vital registration system is very important for development planning, especially in the areas of education, health, housing and food security [6]; [7]. There is therefore, the need improved coverage of the vital events.

Currently, vital registration is in the second expansion phase covering all the 774 Local Government Areas of Nigeria. Unfortunately, with an average of only two (2) registration centres per LGA, which is grossly inadequate considering the landmass, population size, diverse nature of the terrain and large number of localities, vital registration suffers a coverage problem. Disparity in terms of coverage occurs as a result of sizes of catchment areas depending on the available registration centres and or number of informants and or methods adopted, active or passive.

Principally, some of the problems of vital registration identified by the literature in addition to the inadequacy in the number of operational centres and low level of awareness are spatial location/problem of accessibility; and other issues related to the existing vital registration centres. It has been observed by many 
researchers including [8]; [9] that, 'children born in rural areas were less likely to be registered than their counterparts in urban communities'. Whatever method of registration is adopted, it can always be assumed that the greater the distance to the point of registration the more the opportunity and travel costs rise for parents and thus, lesser the rate of registration. More so, accessibility is influenced by location and terrain, the condition of infrastructure such as road and the availability of public transport as rightly opined by [5]. It has therefore, been widely acknowledged that, a significant barrier to birth registration is geographic distance to the nearest registration facility [10]; [11]; [12].

In general terms, birth registration coverage has been low in Gombe State and even the percent distribution of registered live births by residential sector (urban/rural) as indicated in [13] is 65.33 for urban and 34.67 for rural. This indicates lower coverage at the latter residential sector compared to the former and the difference is substantial.[14]. And the role played by the location of the registration centres in determining differential levels of birth registration coverage has been given less attention by researchers.

Since the location of registration centres plays a very important role in the efficient conduct of the registration exercise, research into it in a young but rapidly developing State like Gombe is quite worthy of undertaking. This research work therefore, aims to answer the following questions: Are the locations of the current operational vital registration centres appropriate in relation to the localities within their catchment areas? What is the relationship between level of patronage of the services and distance from the registration centres?

The main aim of this study is to assess the levels of spatial accessibility and efficiency of the birth registration centres to the people of Gombe State. The objectives of this research are:- Identifying and mapping out the locations of the existing Vital Registration Centres in relation to their areas of coverage using GPS and GIS technology; examining and assessing the efficiency levels of the registration centres and rank them according to their captured birth events and the population of their catchment areas and according to LGAs and determining the spatial accessibility of the registration centres to all the localities in their catchment areas.

There is a large body of literature on locational analysis and the application of location-allocation models to public sector services. This is because since 1960's the models have been applied to a wide variety of problem contexts [15]; [16]; [17]. Thus, studies on the location of other infrastructures such as health facilities, using location-allocation models and gravity model have received a lot of attention. There have also been even comprehensive reviews of location-allocation models provided by [18]. They classified these models by sector (public \& private), formal model structure (P-median problems \& covering problems) and the nature of the real world. However, relatively very few if any studies exist on its application to vital registration centres.

For instance, [19] examined availability, geographical accessibility and efficiency levels of primary health centres (PHCs) and private registered medical practitioners (RMPs) in India. It was observed that, location decisions of both types of these services do not correspond effectively to the needs of rural population. Also, most of the time administrative, political and economic factors supersede location-suitability of new services resulting into inter-section and interregional disparities. However, the re-location of any service may not be feasible economically, but location-allocation models can be used to identify new potential locations. Other similar studies include: [20]; [21]; [22]; [23]; [24]; [25]; [26]; [27]

A number of other studies have also indicated the effect of geographic barrier though not in detail and locally specific, on the effectiveness of vital registration system, especially using the passive model (the registrar waiting for the registrants at the registration center) of the registration. Examples of such studies include those by [10]; [5]; [9]; [28]. In fact, [28] applied GIS in assessing existing birth registration centres in Gombe LGA. The study was however restricted to Gombe LGA which is an urban setting and the GIS application too was limited to locating the registration centres for easy access and retrieval of information only. Also, [29] has applied GIS to study hospital availability and accessibility in Gombe LGA. The quantification and understanding of such effects were however, not treated anywhere in detail. Studies where they exist have employed highly aggregated data at macro and country level unit of analysis. These are usually of limited value to explain grassroots scenarios. Hence, there is a knowledge gap in this regard, more especially, in terms of the magnitude of the effect of distance in a particular area.

Thus, in the light of the fact that location of registration centres plays very important role in the efficient conduct of birth registration exercise, research into it in a young but rapidly developing State like Gombe is quite worthy of being undertaken. This is the focus of this research work.

This research is significant because the results will assist population planners and policy makers in the National Population Commission and Gombe State Government to achieve their goal of 100\% coverage of the vital events by the year 2015 .

First, accurate information and maps are provided about where patronages of such services are best received and where patronage is low (geographic disparities of the registration) and hence these will serve as models and proto types for planners. 


\subsection{Study Area}

Gombe State occupies a total land area of about 20,265 sq. km and made up of eleven (11) local government areas. It is located between latitude $9^{\circ} 30^{\prime}$ and $12^{\circ} 30^{\prime}$ north and longitude $8^{0} 45^{\prime}$ and $11^{\circ} 45^{\prime}$ east. It shares boundaries with Yobe in the north, Borno State in the east, Adamawa and Taraba in the south and Bauchi in the west (see fig. 1). It has a total provisional population of 2,353,879 which comprises of 1,230,722 males and 1,123,157 females (National Population Commission, 2006). The State is characterized by mixed ethnicity.

\section{Figure 1: Gombe State Showing the Study Area (The Selected LGAs)}

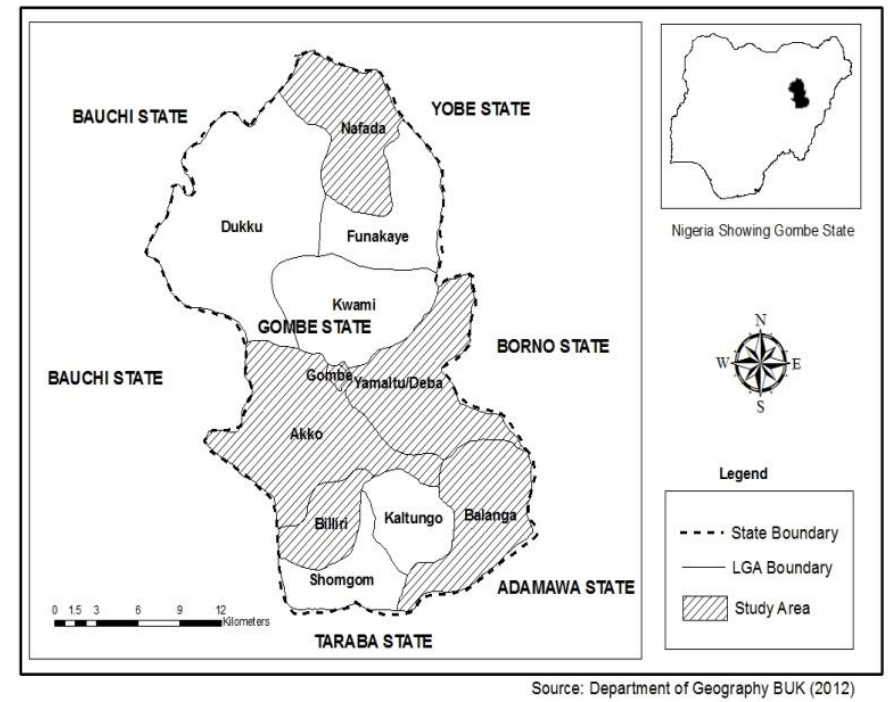

\subsection{Data Types and Data Sources}

\section{Research Methods}

To achieve the stated objectives of this study, two major sources of data (primary and secondary) were explored. Both quantitative and qualitative research strategies were also adopted for this study.

\subsection{Geometric and Attribute Data Collection}

Since all the above exercises were complemented conscientiously with field observations, geocoordinate samples from the localities were collected at the sites, using GPS (one reading in each locality) and the list of the existing vital registration centres were obtained from National Population Commission. For each sampled village, one GPS reading was collected, giving the total of about twelve (12) localities in each LGA (the two (2) vital registration centres and ten (10) sampled localities) and a total of about one hundred and ninety-nine (199) localities in the State.

The attribute data in the form of tables generated from vital registration forms on daily and monthly basis found in annual reports of Gombe State were obtained from National Population Commission. Other attribute data are the population of all the sampled locations and the number of captured events from each sampled locality and each vital registration centre.

The study is restricted to six purposively sampled out of the eleven LGAs in the state and the data spanned over the period of eight years (2000-2008). This is because, before year 2000 the services were carried out on skeletal basis and awareness was relatively lower. Maps and locality lists were collected from the National Population Commission and Gombe State Ministry of Land and Survey and geo-coordinates/Euclidean distances were recorded on a GIS platform.

\subsection{GIS Demarcation of Catchment Areas of Vital Registration Centres}

The road networks of all the sampled LGAs were acquired in the GIS platforms and accessibility was assessed using Euclidean distance measurements. All the accessibility characteristics were stored in a relational database system linked to the GIS database. They were then all used to obtain the partitioning of the catchment areas and the location of the registration centres.

\subsection{Analytical Techniques:}

Data collected from the field were subjected to mathematical and statistical analyses, such as ranking, percentages, charts etc. Registration coverage in this study is the proportion of the registered births to the 
estimated births in an area. The Crude Birth Rate (CBR) of 40 per 1000 was used to calculate the estimated births based on its projected population from 1991.

\section{Results And Discussions}

\subsection{Mapping of the Existing Vital Registration Centres and their Catchment Areas}

Fig. 2 shows the current registration centres in the six sampled LGAs whose locations were captured using GPS. It indicates that Gombe LGA has a large number of the centres on its relatively smaller land area of $53 \mathrm{KM}^{2}$. Thus, accessibility to those centres by its population and those from neighbouring LGAs like Akko and Yamaltu-Deba where some of their localities are engulfed by Gombe metropolis is noticeable. Some parents from those LGAs register their children's births in Gombe rather than travelling to their LGAs' registration centres which are located farther away from their areas of residence.

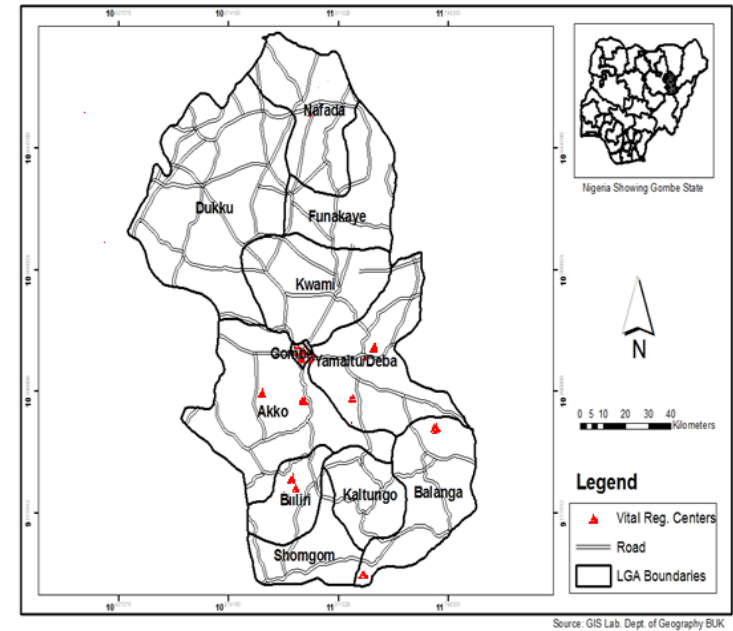

Figure 2: Gombe State Showing the Existing Vital Registration Centres

\subsection{Birth Registration Coverage by Registration Centres}

Table 1 presents levels of birth registration coverage and non-coverage by registration centres (current) in the six sampled LGAs. It further indicates that all the remaining five rural LGAs have over three-quarters (8 in 10) of their children's births not registered and thus, there was a larger percentage of registration over 6 in 10 in Gombe LGA compared to rural areas with only about 2 in 10. In fact, according to [5] and [9], in many developing countries, disparities in terms of birth registration coverage between regions and between urban and rural areas exist. For example in India, urban areas have higher registered birth rates than the rural and geographically inaccessible areas because civil registries are often centralized. Similarly, because the registration process is often carried out in hospital, babies born at home are less likely to be registered.

Table 2 displays the birth registration coverage by ranking of the centres. Out of about 22 registration centres (this does not include registration centres that had no registrars during the period under study), half of this number has registration coverage that is greater than $100 \%$ and all the centres are in Gombe LGA, the State capital. The high rate of registration in urban Gombe as against the other centres is attributable to the existence of large number of registration centres, large influx of people into it during the period under study, some backlogs of unregistered children within that age range were registered during the period under study, while people from other neighbouring LGAs like Akko and Yamaltu-Deba were found to have registered their births in Gombe LGA. Figures 3,4,5,6 and 7 show the designated catchment areas of the registration centres and $5 \mathrm{~km}$ buffers around the centres indicating areas of high registration.

Table 3 illustrates levels of birth registration coverage by LGA and by year of registration. Table 4 shows the coverage and ranking by LGA. To have fair ranking of the selected LGAs, the population sizes and the expected crude birth rates during the period under study were all considered. Surprisingly, of the six (6) sampled LGAs, only one (1) LGA that is, Gombe has registration coverage of over $100 \%$ and above, while the remaining ones have only between $7 \%$ to $20 \%$.

Table 1: Birth Registration Coverage and Non- Coverage by Registration Centres (2000-2008)

\begin{tabular}{|l|l|l|l|l|l|l|l|l|}
\hline S/N & LGA & $\begin{array}{l}\text { RCen } \\
\text { Code }\end{array}$ & Rcen & CBR T & Brec T & Diff. & \% Covered & $\begin{array}{l}\text { \% not } \\
\text { covere } \\
\text { d }\end{array}$ \\
\hline 1 & AKKO & 1 & kumo & 57097 & 9,683 & 47,414 & 17 & 83 \\
\hline & & 2 & Pindiga mater & 43600 & 6,002 & 37,598 & 14 & 86 \\
\hline
\end{tabular}


Locational and Coverage Analysis of the Vital Registration Centres in Gombe State

\begin{tabular}{|c|c|c|c|c|c|c|c|c|}
\hline \multirow{3}{*}{2} & BALANGA & 1 & Talasse & 25013 & 4,150 & 20,863 & 17 & 83 \\
\hline & & 2 & Bambam & 26100 & 2,992 & 23,108 & 11 & 89 \\
\hline & & 3 & Gelengu & 12000 & 793 & 11,207 & 7 & 93 \\
\hline \multirow[t]{2}{*}{3} & BILLIRI & 1 & $\begin{array}{ll}\text { NPC } & \text { OFF } \\
\text { BLR } & \end{array}$ & 26180 & 6,079 & 20,101 & 23 & 77 \\
\hline & & 2 & Gen Hos BLR & 34303 & 8,400 & 25,903 & 24 & 76 \\
\hline \multirow[t]{11}{*}{4} & GOMBE & 1 & NPC ST. OFF. & 7988 & 9,989 & $-2,001$ & 125 & -25 \\
\hline & & 2 & $\begin{array}{ll}\text { NPC } & \text { LGA } \\
\text { OFF } & \\
\end{array}$ & 9761 & 11,001 & $-1,240$ & 113 & -13 \\
\hline & & 3 & FMC GME & 6754 & 10,198 & $-3,444$ & 151 & -51 \\
\hline & & 4 & Spel. Hosp & 9765 & 9,722 & 43 & 100 & 0 \\
\hline & & 5 & NasHosp & 7542 & 8,851 & $-1,309$ & 117 & -17 \\
\hline & & 6 & UrbMatn & 7784 & 9,311 & $-1,527$ & 120 & -20 \\
\hline & & 7 & Pan Matn & 5443 & 8,801 & $-3,358$ & 162 & -62 \\
\hline & & 8 & BolMatn & 8776 & 9,132 & -356 & 104 & -4 \\
\hline & & 9 & Town Matn & 7886 & 9,887 & $-2,001$ & 125 & -25 \\
\hline & & 10 & T/wada PHC & 4364 & 8,954 & $-4,590$ & 205 & -105 \\
\hline & & 11 & H/GanaMatn & 3568 & 7,889 & $-4,321$ & 221 & -121 \\
\hline \multirow[t]{2}{*}{5} & NAFADA & 1 & $\begin{array}{ll}\text { NPC } & \text { OFF } \\
\text { Nafada } & \\
\end{array}$ & 22745 & 4,511 & 18,234 & 20 & 80 \\
\hline & & 2 & BirrI Mat & 19089 & 3,333 & 15,756 & 17 & 83 \\
\hline \multirow[t]{2}{*}{6} & Y/DEBA & 1 & $\begin{array}{ll}\text { NPC } & \text { OFF } \\
\text { Deba } & \end{array}$ & 35527 & 7,099 & 28,428 & 20 & 80 \\
\hline & & 2 & D/KowaMatn & 40786 & 6,498 & 34,288 & 16 & 84 \\
\hline
\end{tabular}

Source: Computed from NPC, Abuja Figures: 2008. N.B.-Rcen=Registration Centre; Brec T=Birth Record Total; CBR T=Crude Birth Rate Total

Birth Registration Coverage by LGA

Table 2: Ranking of Vital Registration Centres According to \% Coverage of Registered Births (2000-

\begin{tabular}{|c|c|c|c|c|c|c|}
\hline $\mathbf{S} / \mathbf{N}$ & & LGA & $\begin{array}{l}\text { Rcen } \\
\text { Code }\end{array}$ & Rcen Name & $\%$ Coverage & $\begin{array}{l}\text { Rankin } \\
\text { g }\end{array}$ \\
\hline 1 & 4 & GOMBE & 11 & HerwaGana Maternity & 221 & 1 \\
\hline 2 & “ & " & 10 & Tudunwada PHC & 205 & 2 \\
\hline 3 & “ & “" & 7 & Pantami Maternity & 162 & 3 \\
\hline 4 & “ & “" & 3 & FMC Gombe & 151 & 4 \\
\hline 5 & " & “" & 9 & Town Maternity & 125 & 5 \\
\hline 6 & " & “" & 1 & NPC State Office & 125 & 5 \\
\hline 7 & " & “" & 6 & Urban Maternity & 120 & 7 \\
\hline 8 & “ & " & 5 & NassarawoHosp & 117 & 8 \\
\hline 9 & " & "“ & 2 & NPC LGA Office & 113 & 9 \\
\hline 10 & “ & “" & 8 & Bolari Maternity & 104 & 10 \\
\hline 11 & “ & $"$ & 4 & Specialist Hosp & 100 & 11 \\
\hline 12 & 3 & BILLIRI & 2 & Gen HospBilliri & 24 & 12 \\
\hline 13 & “ & " & 1 & NPC Office Billiri & 23 & 13 \\
\hline 14 & 6 & Y/DEBA & 1 & NPC Office Deba & 20 & 14 \\
\hline 15 & 5 & NAFADA & 1 & NPC Office Nafada & 20 & 14 \\
\hline 16 & $"$ & “ & 2 & Birri Maternity & 17 & 16 \\
\hline 17 & 1 & AKKO & 1 & Kumo Gen. Hosp & 17 & 16 \\
\hline 18 & 2 & BALANGA & 1 & NPC Office Talasse & 17 & 16 \\
\hline 19 & 6 & Y/DEBA & 2 & D/Kowa Maternity & 16 & 19 \\
\hline 20 & 1 & $\mathrm{AKKO}$ & 2 & Pindiga maternity & 14 & 20 \\
\hline 21 & 2 & BALANGA & 2 & Bambam PHC & 11 & 21 \\
\hline 22 & " & “ & 3 & Gelengu Maternity & 7 & 22 \\
\hline
\end{tabular}

Source: Computed from NPC, Abuja Figures: 2008.

The reason for the above high \% in Gombe LGA is traceable to Gombe receiving patronage from neighbouring LGAs. In generality however, the number of registered births for all the LGAs is far lower than the crude birth rates of the period and population under study.

Even comparison of estimated births and registered births coverage in the state made by the vital registration department, Abuja shows that there were 690,905 estimated births and only 166,878 were registered 
from 2000-2007 giving a difference of 524,027 with less than one-third coverage in the whole of the state [13]. Table 4 shows percentage and ranking of coverage and non coverage by LGA.

Table 3: Registered Births By LGA and Year of Registration in the Six SampledLGAs in Gombe State: 2000-2008

\begin{tabular}{|c|c|c|c|c|c|c|c|c|c|c|}
\hline LGA & $\begin{array}{l}\text { Brec T } \\
2000\end{array}$ & \begin{tabular}{|ll} 
Brec & T \\
2001 &
\end{tabular} & $\begin{array}{ll}\text { Brec } & \text { T } \\
2002 & \end{array}$ & $\begin{array}{ll}\text { Brec } & \text { T } \\
2003 & \end{array}$ & $\begin{array}{ll}\text { Brec } & \text { T } \\
2004 & \end{array}$ & $\begin{array}{l}\text { BrecT } \\
2005\end{array}$ & $\begin{array}{|ll|}\text { Brec } & \text { T } \\
2006 & \\
\end{array}$ & \begin{tabular}{|l} 
Brec T \\
2007
\end{tabular} & \begin{tabular}{|l} 
Brec T \\
2008
\end{tabular} & Total \\
\hline AKKO & 9 & 864 & 864 & 781 & 1,014 & 1,014 & 1,885 & 2,341 & 6,913 & 15685 \\
\hline BALANGA & 338 & 681 & 681 & 613 & 214 & 336 & 279 & 3,834 & 959 & 7935 \\
\hline BILLIRI & 1,372 & 2,563 & 2,563 & 2,563 & 199 & 439 & 862 & 2,797 & 1,121 & 14,479 \\
\hline GOMBE & 5,270 & 11,001 & 11,001 & 14,962 & 5,890 & 9,009 & 11,296 & 22,900 & 14,408 & 105,737 \\
\hline NAFADA & 752 & 337 & 337 & 601 & 236 & 373 & 682 & 2,140 & 2,386 & 7844 \\
\hline Y/DEBA & 1,181 & 734 & 734 & 1,315 & 390 & 1,257 & 1,641 & 5,234 & 1,111 & 13,597 \\
\hline TOTAL & 8,922 & 16180 & 16180 & 20835 & 7,943 & 12,428 & 16,645 & 39,246 & 26,898 & 165,277 \\
\hline
\end{tabular}

Source: Fieldwork, 2008

Table 4: Birth Registration Coverage, Non-Coverage, Diff and Ranking by LGA(2000-2008)

\begin{tabular}{|c|c|c|c|c|c|c|c|c|}
\hline $\mathbf{S} / \mathbf{N}$ & LGA & CBR T & BREC T & DIFF & $\begin{array}{c}\% \\
\text { COVERED }\end{array}$ & Ranking & $\begin{array}{c}\% \\
\text { NOT OVERED }\end{array}$ & Ranking \\
\hline 1 & AKKO & 100697 & 15685 & 85012 & 16 & 5 & 84 & 2 \\
\hline 2 & BALANGA & 63113 & 7935 & 55178 & 13 & 6 & 87 & 1 \\
\hline 3 & BILLIRI & 60483 & 14479 & 46004 & 24 & 2 & 76 & 5 \\
\hline 4 & GOMBE & 79631 & 105737 & 26106 & 133 & 1 & -33 & 6 \\
\hline 5 & NAFADA & 41834 & 7844 & 33990 & 19 & 3 & 81 & 4 \\
\hline 6 & Y/DEBA & 76313 & 13597 & 62716 & 18 & 4 & 82 & 3 \\
\hline
\end{tabular}

Source: Fieldwork, 2008

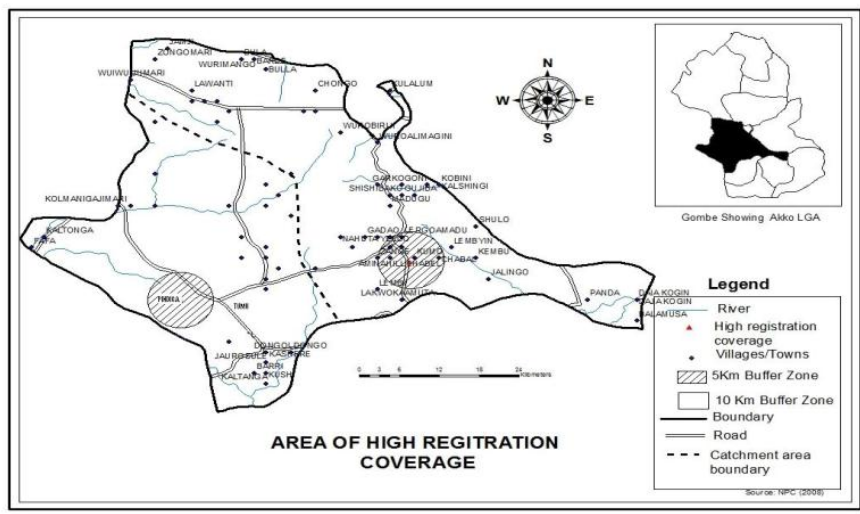

Figure 3: Akko LGA Showing Reg. Centres, Catchment \& Areas Of High Birth Reg. Coverage

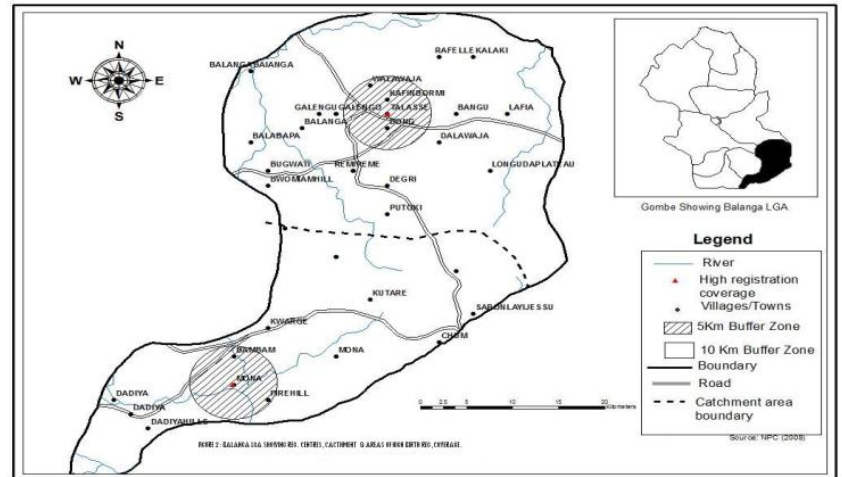

Figure 4: Balanga Lga Showing Reg. Centres, Catchment \& Areas of High Birth Reg. Coverage 


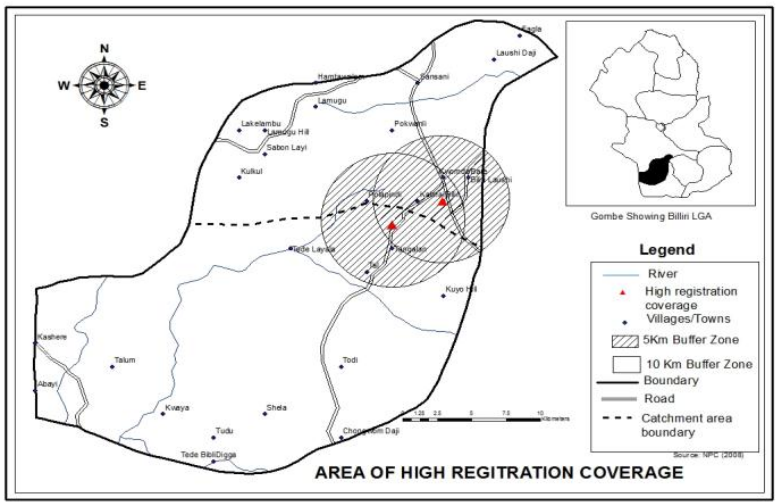

Figure 5: Billiri LGA Showing Reg. Centres, Cacthment \& Areas of High Birth Reg. Coverage

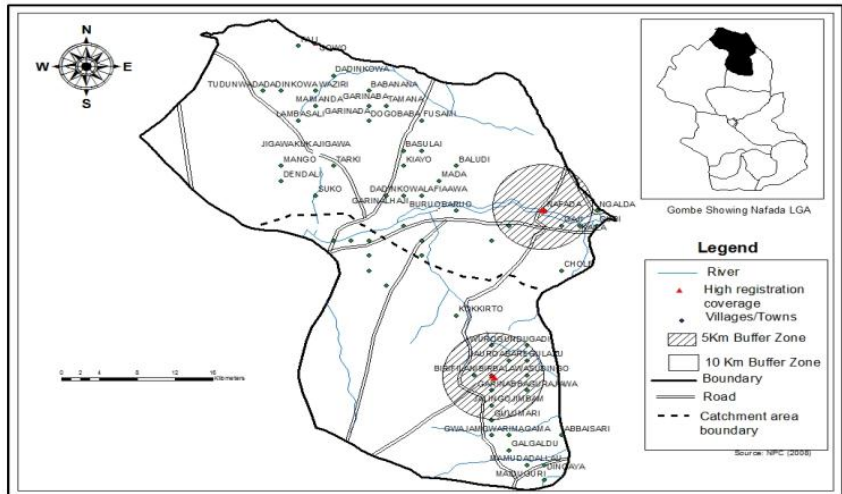

Figure 6: Nafada LGA Showing Reg. Centres, Catchment \& Areas of High Birth Reg. Coverage

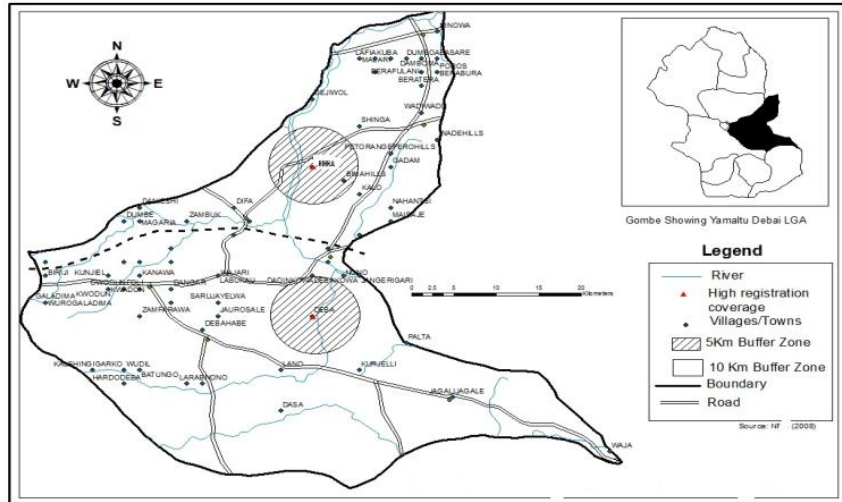

Figure7: Yamaltu-Deba LGA Showing Reg. Centres, Catchment \& Areas Of High Birth Reg. Coverage

\section{Catchments Areas}

3.3 Spatial Accessibility of all the Registration Centres in Relation to Localities intheir

The effect on accessibility of adding 1-10 new registration centres in each of the five rural LGAs using total weighted distance/average settlement distance objective can be seen in figures 8, 9, 10, 11 and 12 .

The Nagfur report in India as cited by [29] recommended that areas lying $4 \mathrm{~km}$ from transportation point are 'fairly accessible', beyond $8 \mathrm{~km}$ are 'inaccessible' and beyond $16 \mathrm{~km}$ are 'very inaccessible'. For the purpose of this study, an area is considered as having a good access if it is located on a flat land within $4-5 \mathrm{~km}$ radius (trekable distance) from a facility according to [30] and within $10 \mathrm{~km}$ as fairly inaccessible. Table 5 highlights accessibility statistics for all the registration centres in the selected LGAs. [32] also suggested something similar to this assertion.

Fig. 8 shows that for Akko LGA, the average weighted distance expressed in kilometer decreases from $24.12 \mathrm{~km}$ with 2 registration centres to only $4.02 \mathrm{~km}$ with 12 centres. That means, if the number of registration cenres could be optimally increased to 12 , all the localities within a catchment area would averagely be located 
within only $4.02 \mathrm{Km}$. The same thing is applicable to all the LGAs as displayed by their respective figures. The furthest distance in the situation of 2 centres with respect to Akko LGA, is $52.62 \mathrm{~km}$, coming down to as low as only $8.77 \mathrm{~km}$ in the event of 12 registration centres.

Fig. 9 indicates that, the average weighted distance in Balanga LGA decreases from $12.54 \mathrm{~km}$ with 2 registration centres to $2,09 \mathrm{~km}$ with 12 registration centres. In this case, the furthest distance is $26.98 \mathrm{~km}$ with 2 centres and only $4.50 \mathrm{~km}$ with 12 centres. The average catchment population also reduced from 105,745 to 17,624 respectively. Balanga LGA however, has a difficult terrain and therefore, the lower the distance to be travelled by a registrant, the better.

For Gombe LGA, the average weighted distance is only $1 \mathrm{~km}$ under the present situation of 11 registration centres. Each of the 11 centres serves only an average of 24, 259 people as against for instance, Akko LGA with only 2 registration centres, and each serving an average of 168,718 people. That means, in Gombe LGA with additional 10 registration centres, the average catchment population of 12,707 people would be served and thus fractions of a kilometer in terms of average weighted distance would be covered by registrants. In practical terms however, Gombe LGA registration centres may be serving the neighboring LGAs of Akko Yamaltu-Deba.

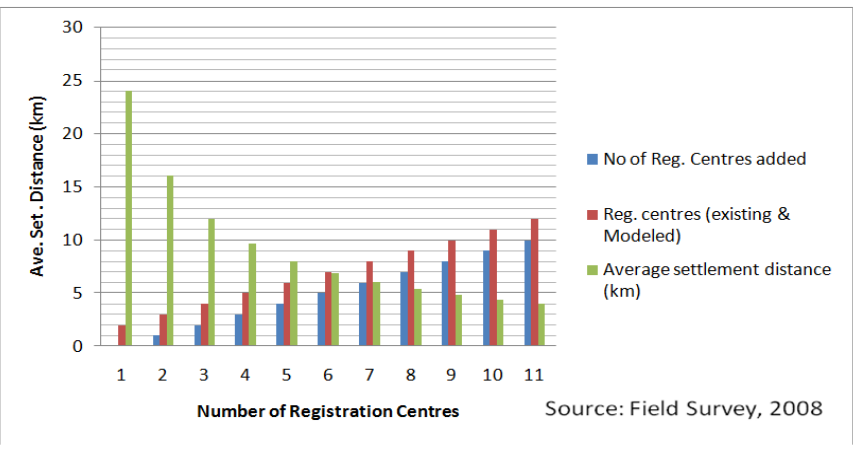

Fig. 8: Accessibility Statistics for Akko LGA's Current and Potential Vital Registration Centres

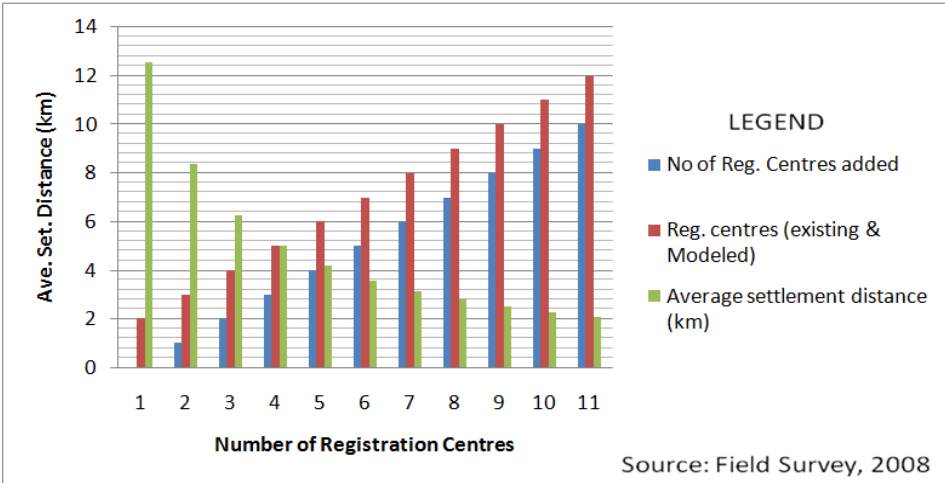

Fig. 9: Accessibility Statistics for Balanga LGA’s Current and Potential Vital Registration Centres

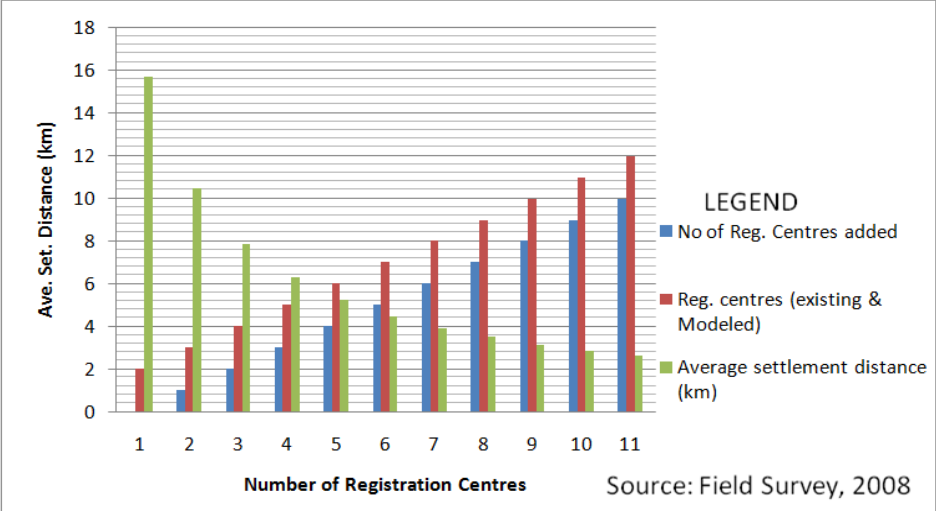

Fig. 10: Accessibility Statistics for Billiri LGA’s Current and Potential Vital Registration Centres 


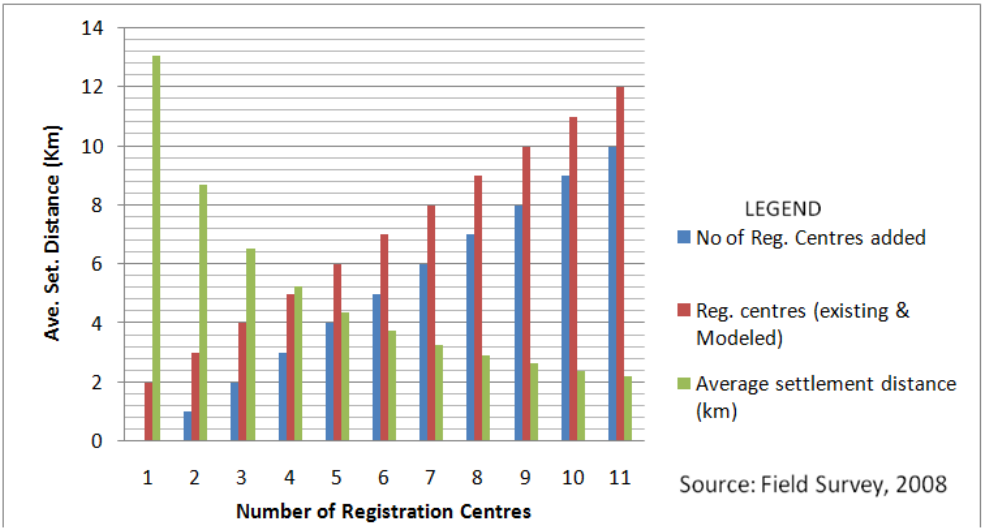

Fig. 11: Accessibility statistics for Nafada LGA's current and potential vital registration centres

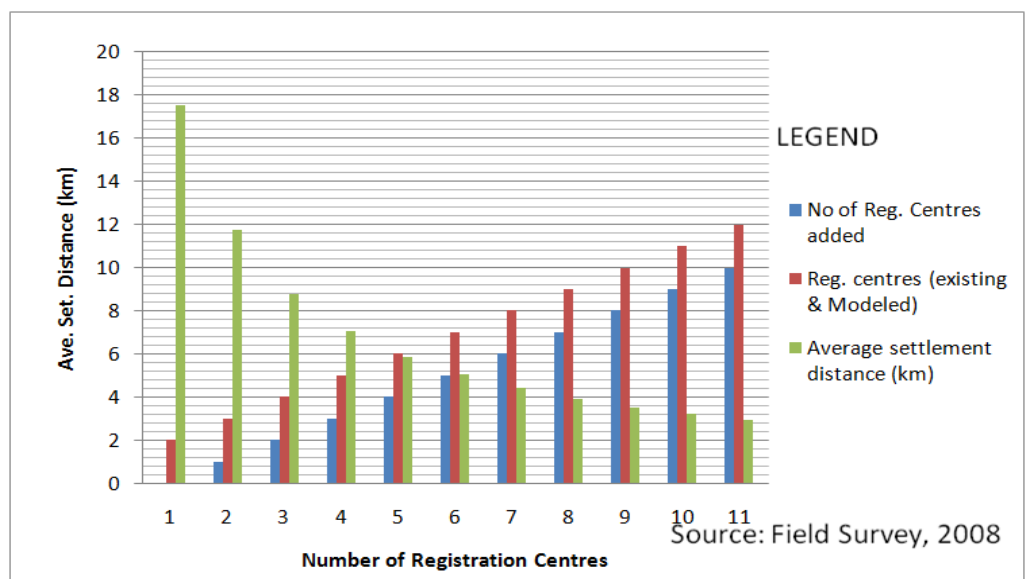

Fig. 12: Accessibility Statistics for Y/Deba LGA's Current and Potential Vital Registration Centres

\subsection{Conclusion}

\section{Conclusion And Recommendations}

It is clear from this study that accessibility affects vital registration coverage. This study provides information and maps about where patronages of such services are best received and where patronage is low (geographic disparities of the registration) and hence these will serve as models and proto types for planners. They will thus, be useful for determining where to launch new birth registration campaign and for tracking future progress by comparing birth registration levels at different points in time and different places in the state. Distance to registration has also been demonstrated by this study as having significant negative effect on birth registration coverage, however Euclidean distance measurement was used and in only the six sampled LGAs out of 11 LGAs. Hence, other aspects of accessibility indexes such as cost and time could be used and extension of such a study to other LGAs could immensely aid planners in planning for any future establishment of registration centres.

A number of factors however, posed some inherent limitations to this study. First of all, as the 2006 census figures were yet to be disaggregated to locality levels, the 1991 locality population was projected by the researcher and used for this work. Second, a crude birth rate index was also used for this study, instead of the actual birth rates since vital registration in a Nigeria suffers from completeness in coverage as well as scope.

\subsection{Recommendations}

i. Establishment of more functional registration centres especially at health centres that are centrally located, coupled with intensive enlightenment campaigns on the importance of birth certificate at the grass root level to be undertaken by all the key stake holders such as Traditional Councils, media, Local Government Officials, Opinion leaders and NGOs among others should be given much priority.

ii. In general, a long-term approach is needed to create birth registration systems that are permanent and sustained to generate consistent supply and demand. Birth Registration should be addressed as a core development issue alongside poverty reduction and universal access to basic services [7]. Thus, it has to be attacked from all angles viz: legal, economic, social, 
political and geographical. This is because the system itself is a multi faceted phenomenon like poverty or underdevelopment.

\section{References}

[1] National Population Commiss. (2004) Manual on Registration of Births and Deaths. National Population Commission. Abuja, Nigeria.

[2] Linder, Forrest E. (1998). Methods for Measuring Population Change in, Public Health Service Publications No. 1000-series 2, No.32.

[3] Wikipedia- Free Encyclopedia (2008).

[4] National Population Commission (2006). Vital Registration Program in Nigeria: Problems and the Way Forward - A Lead Paper Delivered at the LG Vital Registration Sensitization Workshop. NPC, Abuja.

[5] UNICEF (2005). The 'Rights' to Start Life. Innocenti Digest Report.

[6] Lucas, David (2003). 'Registration, Administrative and Qualitative Data', In: Beginning Australian Studies.

[7] Aves, Salvador A. (2004). Making Civil Registration System work better through the Inception of the Barangay Civil Registration System: A Strategic Maneuvering. In $9^{\text {th }}$ National Convention on Statistics (NCS)

[8] Ayeni, O. (1980). A vital registration model for Nigeria In: Population Association of Nigeria- Population Data Assessment in Nigeria. Proceedings No 1, Pp. 77-86.

[9] Duze, Mustafa C. (1995). Vital registration in selected developed anddeveloping countries in: JOSAMS (Journal of Social and Management Studies). Vol. 2, Pp 27-35.

[10] United Nations General Assembly (2002). Child's Right Charter No. 7

[11] Muzzi, Mariana (Jan. 2010). UNICEF Good Practices in Integrating Birth Registration into Health Systems (2000-2009): Case Studies: Bangladesh, Brazil, the Gambia and Delhi, India. New York, UNICEF

[12] Bathia, Jayant K. (2007) 'Situation Analysis Report' on the Status of VRS inKano State Submitted to National Population Commission.

[13] Zubema, J.D. (2009). Sustainable Birth Registration System in Nigeria: A paper presented at a workshop organized by the UNICEF "D" Field Office in Crest Hotel, Jos: (22-23 July, 2009).

[14] Inyang, Soddy I. and Asiribo, Osebi (1995). Forecasting Import Traffic Distribution at the Apapa Port, Nigeria; in JOSAMS. Vol. 2, FSMS.

[15] Drezner, Z. \& Hamacher, H.(2002) Facility location: A survey of application\& methods. New York, Springer.

[16] Mirchandani, P. \&Reill, J. (1987). Spatial Distribution Design for Fire Fighting Units. In Ghosh, A. \& Rushton, G. (eds.), Spatial Analysis \& Location-Allocation Models. New York, Van Nostrand Reinhold Company Inc.

[17] Ghosh, A. and G. Rushton (1987). Spatial analysis and location-allocation models. New York, Van Nostrand Reinhold Co. Inc.

[18] Hodgson, M., Rosing, K. \&Shmulevitz, F. (1993). A review of Location-Allocation Application Literature. Studies in Location Analysis, Vol. 5, pp. 3-29.

[19] Kumar, Naresh (2005) Locational Analysis of Public and Private Health Service in Bhiwan Districts (India) - 1981 to 1996. Centre for the Study of Regional Development, Jarvaharial Nehru Univ. N. Delhi

[20] Tewari, V. K. (1992). 'Improving Access to Services and Facilities in Developing Countries', International Regional Science Review, Vol. 15, No.1, Pp. 25-37

[21] Taylor, P. J. (1977). Quantitative Methods in Geography: An Introduction to Spatial Analysis, Boston: Houghton Miffin. S.

[22] Sanasi-Najad, S. H. and Faraji-Sabokbar, H. A. (2007). Using Location-Allocation Models for Regional Planning in GIS Environment.

[23] Pearson, Jesse K. (2007). A comparative business site-location feasibility analysis, using Geographic Information Systems and Gravity Models. Vol. 9, Papers in Resource Analysis. Retrieved on $12^{\text {th }}$ July, 2008 from http//www.gis.smumn.edu

[24] Matisziw, T. \&Murry, A. (2009). Sitting a facility in continuous space to maximize coverage of a region. Socio-Economic Planning Sciences, Vol. 43, pp. 131-139.

[25] Longley, P. \& Batty, M. (2003). Advanced Spatial Analysis: the case book of GIS. California: ESRI.

[26] Kuhn, W. (2003). 'Semantic location analysis' in: International Journalof Geographic Information Science. Vol.17, No. 5, Pp 405409.

[27] Algharib, Saad M. (2011). Distance \& coverage: An assessment of location-allocation models for fire stations in Kuwait city, Kuwait. An unpublished PhD dissertation submitted to Kent State University, USA.

[28] Maigari, Jude Y. (2007). GIS Application in. Assessing Existing Birth Registration Centres in Gombe LGA. Unpublished PGD in GIS submitted to Dept. of Geo-informatics, Federal School of Surveying, Oyo.

[29] Olorunsaiye, J.B. (2007). GIS Application in Health Care Delivery: A Case Study of Hospital Availability and Accessibility in Gombe LGA of Gombe State. Unpublished PGD in GIS submitted to Dept. of Geo-Informatics, Federal School of Surveying, Oyo.

[30] Mohammed, A. (2011). Geographic analysis of rural mobility in Kano Region. An unpublished PhD Theses submitted to Geography Dept. BUK, Nigeria

[31] Oppong, J.R. nd M.J. Hodgson (1994). 'Spatial accessibility to health care facilities in Suhun district, Ghana,' in: Professional Geographer. Vol. 46, No. 2: Pp. 199-202.

[32] Dubuc, S. (2009). GIS-based accessibility analysis for network optimal location model. 